\title{
NLRP3 polymorphism is associated with protection against human T-lymphotropic virus 1 infection
}

\author{
Anselmo Jiro Kamada ${ }^{1}$, Alessandra Pontillo²/+, Rafael Lima Guimarães ${ }^{1}$, Paula Loureiro ${ }^{3}$, \\ Sergio Crovella', Lucas André Cavalcanti Brandão ${ }^{4}$
}

\author{
${ }^{1}$ Departamento de Genética ${ }^{4}$ Departamento de Patologia, Universidade Federal de Pernambuco, Recife, PE, Brasil \\ ${ }^{2}$ Laboratório de Imunogenética, Departamento de Imunologia, Instituto de Ciências Biomédicas, Universidade de São Paulo,

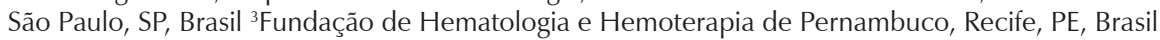

Inter-individual heterogeneity in the response to human T-lymphotropic virus 1 (HTLV-1) infection has been partially attributed to host genetic background. The antiviral activity of the inflammasome cytoplasmic complex recognises viral molecular patterns and regulates immune responses via the activation of interleukin (IL)-1 family (IL-1, IL-18 and IL-33) members. The association between polymorphisms in the inflammasome receptors NLRP1 and NLRP3 and HTLV-1 infection was evaluated in a northeastern Brazilian population (84 HTLV-1 carriers and 155 healthy controls). NLRP 3 rs $10754558 \mathrm{G} / G$ was associated with protection against HTLV-1 infection $(p=0.012$; odds ratio $=0.37$ ). $r$ s 10754558 affects NLRP3 mRNA stability; therefore, our results suggest that higher NLRP3 expression may augment first-line defences, leading to the effective protection against HTLV-1 infection.

Key words: NLRP3 - NLRP1 - single nucleotide polymorphisms - innate immunity - HTLV-1

The initial stage of human T-lymphotropic virus 1 (HTLV-1) infection involves cell-cell transmission of HTLV-1 from infected to uninfected T-lymphocytes, followed by the clonal expansion of infected cells, with almost undetectable levels of circulating virions (Pique \& Jones 2012). The pathogenic outcome has been strongly associated with the clonal expansion and infiltration of infected lymphocytes into affected tissues (Lairmore et al. 2012), while efficient antigen presentation and cytolytic activity of HTLV-1-specific $\mathrm{CD} 8^{+}$cytotoxic T-lymphocytes have been associated with HTLV-1 proviral load (PVL) control. Several cytokine-coding genes and human leukocyte antigen variants were previously described as important restriction factors of PVL and HTLV-1 pathogenesis; therefore, the genetic backgrounds of several host immunity components have recently been investigated (Vine et al. 2002, Haddad et al. 2011, Rocha-Júnior et al. 2012).

The early innate response to several viruses such as influenza virus, Sendai virus, hepatitis $\mathrm{C}$ virus (HCV) and adenovirus consists of interleukin (IL)- $1 \beta$ production via inflammasome activation. The inflammasome is a cytosolic complex that detects pathogen or danger-associated molecular patterns and leads to the activation of caspase-1, the enzyme responsible for pro-IL-1ß/IL-1ß conversion (Gram et al. 2012). Significant expression of IL-1ß has been reported to be induced by HTLV-1 transactivator protein in macrophages, microglial cells and astrocytes

doi: 10.1590/0074-0276140154

Financial support: FACEPE (APQ-0757-2.02/10)

+ Corresponding author: alepontillo@usp.br

Received 5 May 2014

Accepted 6 August 2014
(Banerjee et al. 2007, Takahashi et al. 2013), suggesting an innate response through inflammasome regulation. Furthermore, the HTLV-1-specific cytolytic response was shown to be modulated by IL-1 in mice because this cytokine enhanced the expansion and tissue localisation of antigen-driven $\mathrm{CD}^{+} \mathrm{T}$ cell (Ben-Sasson et al. 2013).

The inflammasome plays a major role in IL-1ß production and may also be involved in the cytoplasmic recognition of HTLV-1; therefore, we investigated the possible association between selected single nucleotide polymorphisms (SNPs) in the inflammasome receptor genes NLRP3 and NLRP1 and susceptibility to HTLV-1 infection in HTLV-1-infected patients and controls from northeastern Brazil.

Eighty-four HTLV-1-infected subjects $(46.32 \%$ males, $53.68 \%$ females; mean age $=45.29 \pm 2.60$ years) were enrolled from the metropolitan area of Recife, state of Pernambuco (PE), Brazil. All participants were screened for the presence of plasma anti-HTLV-1 antibodies (ELISA: Murex Biotech Limited, UK) and positivity was confirmed by qualitative nested-polymerase chain reaction (PCR) analysis performed at the Hemope Foundation (blood center of PE). A total of 155 healthy controls (HCs) $(46.46 \%$ male, $53.54 \%$ females; mean age $=21.72 \pm 2.45$ years) with negative HTLV-1 serology and negative qualitative PCR were recruited as control subjects from the same metropolitan area at Hemope. Written informed consent was obtained according to the Hemope Ethical Committee (protocol 016/2010).

The HTLV-1 carriers and HCs were admixed northeastern Brazilians. The ethnicity of the patients and HCs was analysed using ancestry markers as reported by Kosoy et al. (2009) and the ethnic background results demonstrated similar frequencies of approximately $58 \% \mathrm{Cau}-$ casian, 25\% African and 17\% Amerindian backgrounds.

DNA was obtained from the peripheral blood of uninfected HCs and HTLV-1 carriers using the "salting 


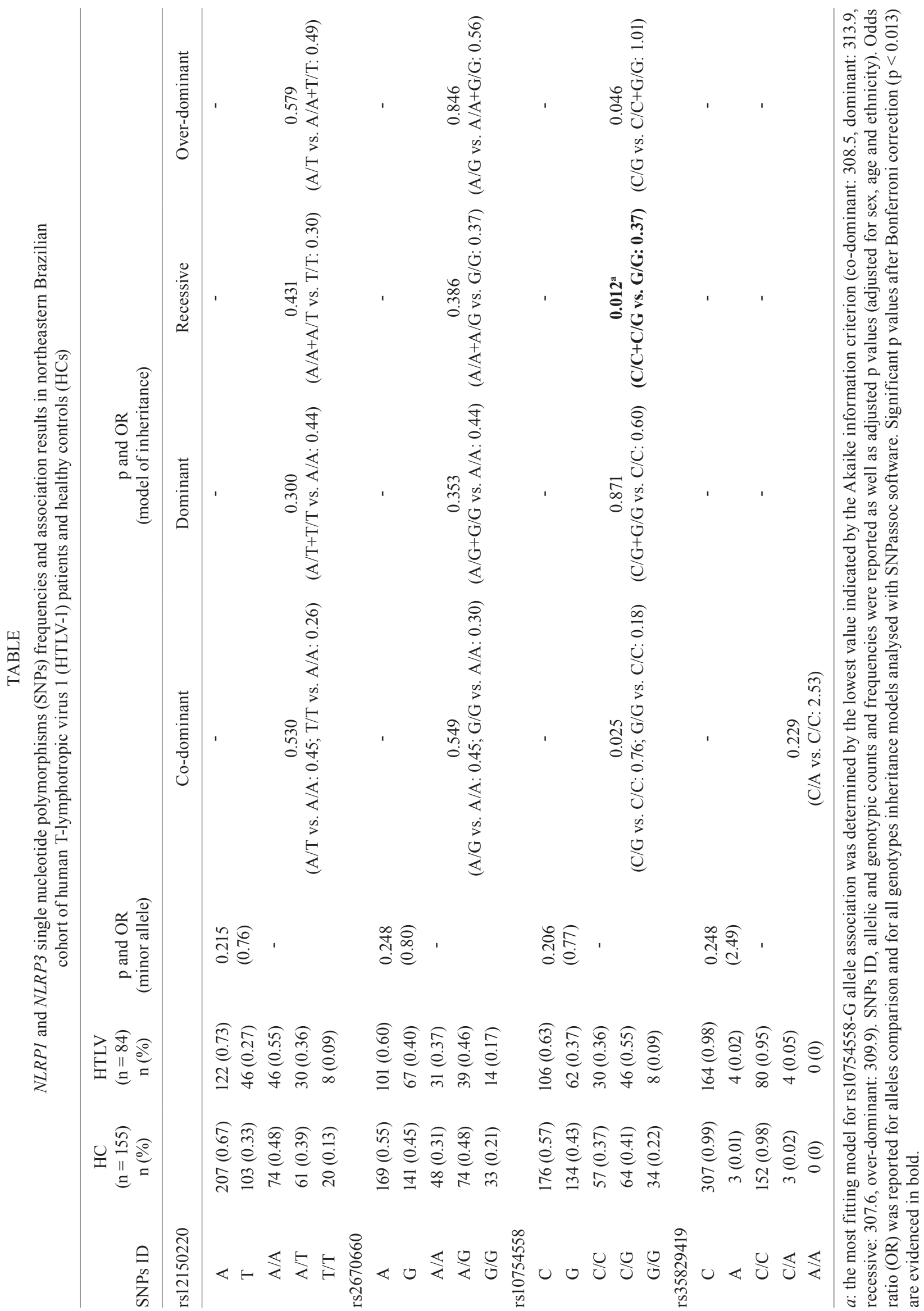


out" protocol for genomic DNA extraction (Miller et al. 1988). SNPs in the NLRP3 and NLRP1 genes were selected considering their reported functional effects on inflammasome biology and IL-1ß secretion (Glinskii et al. 2009, Hitomi et al. 2009, Verma et al. 2012, Levandowski et al. 2013). Genotyping was performed using commercially available TaqMan assays (Applied Biosystems, USA). The TaqMan reactions were set up based on the manufacturer's protocol and the samples were run on an ABI7500 Real Time PCR System (Applied Biosystems). Allelic discrimination was performed using the SDS software (v.2.3) (Applied Biosystems).

R software (r-project.org) was used to perform Fisher's exact test and odds ratio (OR) calculations for alleles and haplotypes as well as genotype associations and inheritance modelling (Lewis 2002) (package SNPassoc v.1.5-2). The results are reported as p-values adjusted for sex, ethnicity and age. Formal Bonferroni's correction for the number of SNPs analysed required a significance threshold of $p$ $=0.013(\mathrm{P} 0 / \mathrm{n}, \mathrm{P} 0=0.05, \mathrm{n}=4$ tests $)$. The post hoc statistical power analysis was performed with the G*power software (v.3.0.5), with an alpha-error probability of 0.05 . The Haploview software was used to investigate the association and linkage disequilibrium (LD) pattern and to derive the haplotypes (Barret et al. 2005). According to this software, haplotype frequencies were estimated using the expectation-maximisation (EM) algorithm and haplotype association was evaluated using the chi-square test.

The NLRPI rs12150220 and rs2670660 polymorphisms were not associated with susceptibility to HTLV-1 infection in our case-control cohort because the frequency distribution of these two SNPs was not significantly different among the HTLV-1 carriers and HCs (Table). The two NLRPI SNPs were in LD (D'/LOD = 94), confirming previous studies (Jin et al. 2007). However, the resulting rs12150220-rs2670660 haplotypes (A-A, T-G, A-G) did not appear to be differentially distributed between the cases and controls $(p=0.287, \mathrm{OR}=0.77 ; \mathrm{p}$ $=0.147, \mathrm{OR}=1.40 ; \mathrm{p}=0.810, \mathrm{OR}=0.93$; respectively) (Supplementary data).

The NLRP3 rs35829419 allele and genotype frequency distributions were also similar within the HTLV-1 and $\mathrm{HC}$ groups, with no association observed $(\mathrm{p}=0.248$ and $\mathrm{p}=0.229$, respectively) (Table).

The allelic distribution of the NLRP3 rs10754558 polymorphism did not vary significantly between the cases and controls $(\mathrm{p}=0.206)$. Although the NLRP3 rs10754558 genotype frequencies were not differentially distributed $(\mathrm{p}=0.025)$ (Table) between HTLV-1 patients and $\mathrm{HCs}$, a significant difference was found when a recessive model of rs 10754558 heritage was utilised [lowest value of the Akaike information criterion according to Lewis (2002) and SNPassoc software], suggesting that homozygosity for the minor $\mathrm{G}$ allele confers protection against HTLV-1 infection (G/G vs. C/C + C/G: p $=0.016)$. No association was found using different inheritance models of rs12150220, rs2670660 (NLRPI) and rs35829419 (NLRP3) SNPs ( $\mathrm{p}>0.05$ ).

The presence of the rs $10754558 \mathrm{G}$ allele has been reported to increase the stability of the 3'UTR structure of NLRP3 mRNA, resulting in a higher expression level (Hitomi et al. 2009).
These data suggest that individuals presenting a more stable $N L R P 3$ expression pattern may be more effectively protected against HTLV-1 infection. Stable $N L R P 3$ expression may be the consequence of an increased number of NLRP3 viral-sensing receptors or augmented basal IL- $1 \beta$ production due to the increased expression of NLRP3, which may activate the inflammasome through the recognition of several cell stress molecules (Gram et al. 2012) produced as a result of HTLV infection. We are aware that our study had two major limitations, specifically the extent of size of casuistic and the lack of functional assays, although the effect of the rs $10754558 \mathrm{G}$ allele was previously demonstrated (Hitomi et al. 2009). However, we speculate that NLRP3 may be able to sense HTLV-1 in the cytoplasm of infected cells, in a manner similar to the detection of influenza virus or HCV (Gram et al. 2012). According to this hypothesis, increased NLRP3 expression may confer significant protection against virus infection. However, even if NLRP3 is not involved in sensing HTLV, increased NLRP3 expression may affect the rate of inflammasome activation, leading to greater IL$1 \beta$ production. Inflammasome activation and IL- $1 \beta$ are known to be involved in antigen presentation $(\mathrm{Qu}$ et al. 2009) and T-cell activation (Liu et al. 2013); therefore, we propose that heightened inflammasome activation may contribute to a better anti-HTLV immunologic response. We would also like to emphasise that despite the differences in virus type and infection cycle, our group recently showed that $N L R P 3$ rs 10754558 was similarly associated with HIV-1 infection (Pontillo et al. 2010), with the G/G genotype detected less frequently in HIV+ patients. This finding suggests that through a currently unidentified mechanism, rs10754558 carriers may be protected against viral infection. However, further studies are required to confirm these data in other cohorts and to investigate the functional role of this variation in inflammasome/virus interplay.

\section{REFERENCES}

Banerjee P, Rochford R, Antel J, Canute G, Wrzesinski S, Sieburg M, Feuer G 2007. Proinflammatory cytokine gene induction by human T-cell leukemia virus type 1 (HTLV-1) and HTLV-2 Tax in primary human glial cells. $J$ Virol 81: 1690-1700.

Barrett JC, Fry B, Maller J, Daly MJ 2005. Haploview: analysis and visualization of LD and haplotype maps. Bioinformatics 21: 263-265.

Ben-Sasson SZ, Hogg A, Hu-Li J, Wingfield P, Chen X, Crank M, Caucheteux S, Ratner-Hurevich M, Berzofsky JA, Nir-Paz R, Paul WE 2013. IL-1 enhances expansion, effector function, tissue localization and memory response of antigen-specific CD8 T cells. J Exp Med 210: 491-502.

Glinskii AB, Ma J, Ma S, Grant D, Lim C-U, Sell S, Glinsky G 2009. Identification of intergenic trans-regulatory RNAs containing a disease-linked SNP sequence and targeting cell cycle progression/differentiation pathways in multiple common human disorders. Cell Cycle 8: 3925-3942.

Gram AM, Frenkel J, Ressing ME 2012. Inflammasomes and viruses: cellular defence versus viral offence. J Gen Virol 93: 2063-2075.

Haddad R, Alves DCC, Rocha-Júnior MC, Azevedo R, Pombo-de-Oliveira MS, Takayanagui OM, Donadi EA, Covas DT, Kashima S 2011. HLA-G 14-bp insertion/deletion polymorphism is a risk factor for HTLV-1 infection. AIDS Res Hum Retroviruses 27: 283-288. 
Hitomi Y, Ebisawa M, Tomikawa M, Imai T, Komata T, Hirota T, Harada M, Sakashita M, Suzuki Y, Shimojo N, Kohno Y, Fujita K, Miyatake A, Doi S, Enomoto T, Taniguchi M, Higashi N, Nakamura Y, Tamari M 2009. Associations of functional NLRP3 polymorphisms with susceptibility to food-induced anaphylaxis and aspirin-induced asthma. J Allergy Clin Immunol 124: 779-885.

Jin Y, Mailloux CM, Gowan K, Riccardi SL, La Berge G, Bennett DC, Fain PR, Spritz RA, 2007. NALP1 in vitiligo-associated multiple autoimmune disease. $N$ Engl J Med 356: 1216-1225.

Kosoy R, Nassir R, Tian C, White PA, Butler LM, Silva G, Kittles R, Alarcon-Riquelme ME, Gregersen PK, Belmont JW, De la Vega FM, Seldin MF 2009. Ancestry informative marker sets for determining continental origin and admixture proportions in common populations in America. Hum Mutat 30: 69-78.

Lairmore MD, Haines R, Anupam R 2012. Mechanisms of human T-lymphotropic virus type 1 transmission and disease. Curr Opin Virol 4: 474-481.

Levandowski CB, Mailloux CM, Ferrara TM, Gowan K, Ben S, Jin Y, McFann KK, Holland PJ, Fain PR, Dinarello CA, Spritz RA 2013. NLRP1 haplotypes associated with vitiligo and autoimmunity increase interleukin-1 $\beta$ processing via the NLRP1 inflammasome. Proc Natl Acad Sci USA 110: 2952-2956.

Lewis CM 2002. Genetic association studies: design, analysis and interpretation. Brief Bioinform 3: 146-153.

Liu D, Rhebergen AM, Eisenbarth SC 2013. Licensing adaptive immunity by NOD-like receptors. Front Immunol 44: 1-17.

Miller SA, Dykes DD, Polesky HF 1988. A simple salting out procedure for extracting DNA from human nucleated cells. Nucleic Acids Res 16: 1215.
Pique C, Jones KS 2012. Pathways of cell-cell transmission of HTLV-1. Front Microbiol 3: 1-17.

Pontillo A, Brandão LA, Guimarães RL, Segat L, Athanasakis E, Crovella S 2010. A 3'UTR SNP in NLRP3 gene is associated with susceptibility to HIV-1 infection. J Acquir Immune Defic Syndr 54: $236-240$

Qu Y, Ramachandra L, Mohr S, Franchi L, Harding CV, Nunez G, Dubyak GR 2009. P2X7 receptor-stimulated secretion of MHC class II-containing exosomes requires the ASC/NLRP3 inflammasome, but is independent of caspase-1. J Immunol 182: 5052-5062.

Rocha-Júnior MC, Haddad R, Alves DCC, Wagatsuma VMD, Mendes-Júnior CT, Deghaide NHS, Takayanagui OM, Covas DT, Donadi EA, Kashima S 2012. Interleukin-18 and interferon-gamma polymorphisms are implicated on proviral load and susceptibility to human T-lymphotropic virus type 1 infection. Tissue Antigens 80: 143-150.

Takahashi M, Higuchi M, Makokha GN, Matsuki H, Yoshita M, Tanaka Y, Fujii M 2013. HTLV-1 Tax oncoprotein stimulates ROS production and apoptosis in T cells by interacting with USP10. Blood 122: 715-725.

Verma D, Särndahl E, Andersson H, Eriksson P, Fredrikson M, Jönsson J-I, Lerm M, Söderkvist P 2012. The Q705K polymorphism in NLRP3 is a gain-of-function alteration leading to excessive interleukin-1 $\beta$ and IL-18 production. PLoS ONE 7: e34977.

Vine AM, Witkover AD, Lloyd AL, Jeffery KJM, Siddiqui A, Marshall SEF, Bunce M, Eiraku N, Izumo S, Usuku K, Osame M, Bangham CRM 2002. Polygenic control of human T lymphotropic virus type I (HTLV-I) provirus load and the risk of HTLV-I-associated myelopathy/tropical spastic paraparesis. J Infect Dis 186: 932-939. 